\title{
BANTUAN PEMERINTAH INDONESIA DALAM PENANGANAN PENGUNGSI INTERNASIONAL DARI NEGARA KONFLIK ${ }^{1}$
}

\author{
Nanda Agus Safana Sukma ${ }^{1 *}$, Adie Dwiyanto Nurlukman ${ }^{2}$, Amiludin $^{3}$, Ahmad $^{4}$ \\ Fakultas Ilmu Sosial dan Ilmu Politik ${ }^{12}$, Fakultas Hukum ${ }^{34}$, \\ Universitas Muhammadiyah Tangerang \\ Jalan Perintis Kemerdekaan I No. 33 Cikokol, Tangerang, Banten \\ nandaagussafanasukma@gmail.com
}

\begin{abstract}
This study describes the form of Indonesian government assistance to refugees from conflict countries in the perspective of Human Rights which is currently flooding the capital, especially in Kalideres, West Jakarta. Refugees feel insecure in their own country and ask for protection in other countries, with the context of seeking permanent solutions to problems. This research method is carried out by means of a literature review approach in the form of qualitative descriptive with a systematic literature review. The results showed that the government responded by providing solutions in the form of humanitarian assistance and emergency principles. With that, it ends with the provision of recommendations that are final and binding, in accordance with the established regulations.
\end{abstract}

Keywords: Assistance; Refugees; Human rights.

\begin{abstract}
Abstrak
Penelitian ini menjelaskan bentuk bantuan pemerintah Indonesia terhadap pengungsi dari negara konflik yang sedang membanjiri Ibukota, khususnya di Kalideres, Jakarta Barat, dalam perspektif hak asasi manusia. Pengungsi merasa tidak aman di negaranya sendiri dan meminta perlindungan ke negara lain, dengan konteks mencari penyelesaian masalah yang permanen. Metode penelitian ini dilakukan dengan cara pendekatan kajian pustaka yang berbentuk secara kualitatif deskriptif dengan tinjauan literatur sistematis. Hasil penelitian menunjukkan bahwa pemerintah menyikapinya dengan memberikan solusi berupa bantuan kemanusiaan dan prinsip kedaruratan. Dengan itu, berakhir pada pemberian rekomendasi yang bersifat final dan mengikat, sesuai dengan regulasi yang telah ditetapkan.
\end{abstract}

Kata Kunci: Bantuan; Pengungsi; Hak Asasi Manusia.

\footnotetext{
${ }^{1}$ Artikel ini merupakan hasil penelitian mandiri pada tahun 2020.
} 


\section{A. Pendahuluan}

Proses kompleks dengan berbagai tingkat kesulitan yang terlibat adalah bagian dari migrasi. Model arus migrasi tentang situasi dan kondisi mendorong orang untuk meninggalkan satu tempat ke tempat lain (Nagel \& Boyle, 2020). Rangkaian proses migrasi, tidak terlepas dari sebuah pergerakan arus pencari suaka dan pengungsi (Sheikh \& Anderson, 2018). Orang yang melintasi perbatasan internasional saat melarikan diri dari konflik dan membutuhkan perlindungan karena ketidakmampuannya untuk bisa berada kembali ke negara asalnya disebut pengungsi (Thompson, 2020). Pencari suaka mudah dikenal berpotensi bahaya dan mengancam. Sedangkan pengungsi lebih patuh menunggu proses (Suwardi, 2004). Maka dari itu seorang yang belum diakui statusnya akan dinamakan sebagai pencari suaka, tetapi seorang pencari suaka belum tentu seorang pengungsi. Jika sudah diakui sebagai pengungsi maka akan melekat hak dan kewajibannya terhadap negara pelindung (Hardjaloka, 2015).

Menurut data dari UNHCR (United Nation High Commissioner for Refugee) pada tahun 2016 ada 65,6 juta orang di seluruh dunia secara terpaksa dipindahkan, dimana 22,5 juta di antaranya berstatus pengungsi karena perang saudara, penganiayaan, dan kasus krisis kemanusiaan lainnya (Dreher dkk., 2019). Banyak faktor yang melatarbelakangi, seperti diskriminasi, perang dan kebencana-alaman (Hvass dkk., 2020). Agar memiliki kehidupan yang lebih stabil dan aman, mereka secara terpaksa meninggalkan negara asalnya dan berpindah ke negara lain yang lebih maju, dengan tingkat keberhasilan ekonomi, kesejahteraan sosial, maupun kestabilan politik nya sangat terjamin, seperti negara Jerman, Inggris Amerika Serikat, Prancis, Selandia Baru, Kanada dan Australia (Prastya \& Yuniati, 2015). Suatu dinamika antara negara asal dan negara tujuan, bisa sebagai alasan pentingnya untuk suatu negara menerima kelompok pengungsi dan lebih cenderung memilih tujuan yang mengurangi ancaman terhadap pribadi pengungsi, dengan menemukan proses demokratisasi yang menjadi faktor dalam penentuan dan tujuan pengungsi (Moorthy \& Brathwaite, 2019).

Kasus HAM sudah menjadi bagian dari kajian hukum internasional yang bersifat suatu mekanisme dan perlindungan individu terhadap kekuatan negara (Anggrainy, 2014). Seperti kasus padatnya jumlah pengungsi dari berbagai negara yang menggemparkan masyarakat Kelurahan Kalideres, Jakarta Barat, permasalahan HAM yang terjadi karena tidak terpenuhinya hak hidup mereka sebagai warga negara. Mayoritas mereka yang datang dari negara Afghanistan, Somalia dan Irak. Faktornya karena adanya tekanan, seperti rasisme, agama, kelahiran atau kesukuan. Mereka bersedia tidak kembali ke negaranya, karena pemerintah mereka tidak siap untuk perlindungan. Mereka melarikan diri di bawah tekanan dan datang hanya membawa kebutuhan hidup yang seadanya, hanya mendirikan tenda untuk tempat berlindung. Sebagian dari mereka tidak bisa berbahasa Inggris dengan baik, jadi salah satu faktor penghambat pengungsi dalam bersosial ke masyarakat sekitar. Pengungsi hanya mendapatkan bantuan dari mereka yang menyalurkan bantuan mulai dari perorangan atau kelompok yang murni dari gerakan kemanusiaan (UNHCR, 2020). Fungsi dan peran penggerakan politik sebagai faktor pendorong integrasi tentang kesejahteraan, kualitas hidup, penderitaan, dan kesehatan mental (Barber dkk., 2014).

Indonesia sebagai negara penghubung dalam pergerakan arus migrasi dengan letak garis pantai yang panjang, terletak pada garis silang dan menjadi jalur utama lintas perdagangan dunia dan menyebabkan Indonesia berpotensi sebagai wilayah transit yang aman bagi mereka yang tidak berdokumen (Prastya \& Yuniati, 2015). Berdasarkan data dari (UNHCR, 2020) populasi pengungsi mengalami kenaikan jumlah di tahun 2014-2016: mulai tahun 2014 populasi pengungsi berjumlah 4.131, tahun 2015 berjumlah 4.318, serta tahun 
2016 berjumlah 7.827 yang mana selalu di dominasi oleh Afghanistan.

Berdasarkan gambar 1, per Juli 2020 untuk data yang masuk dan terdaftar oleh UNHCR Indonesia terdapat 13.653 orang asing yang masuk ke Indonesia, yang terbagi menjadi 10.278 pengungsi dan 3.375 masih dinyatakan sebagai pencari suaka, yang mana terdapat $28 \%$ anak-anak, $72 \%$ orang dewasa yang terdiri dari $27 \%$ perempuan dan $73 \%$ laki-laki. Para pengungsi yang datang ke Indonesia dari berbagai negara, diantaranya 56\% Afghanistan, 10\% Somalia dan 6\% Iraq. Total 577 anak-anak pengungsi yang terdaftar di sekolah nasional yang didanai hampir seluruh total kebutuhannya dan didanai oleh beberapa negara yang berkontribusi sukarela yaitu Autralia, Jepang, Amerika Kanada, Spanyol, Uni Eropa dan pendonor swasta lainnya. Indonesia memberikan dana operasional hanya $45 \%$ dari kebutuhan atau sebesar USD \$9.700.000. 643 total pengungsi adalah mereka yang tidak memiliki kewarganegaraan. Tahun 2019, total 720 pengungsi sudah diterima oleh negara ketiga, dengan kategori 663 untuk pemukiman kembali dan 57 untuk sponsor pribadi, serta ada 5 kota yang hadir di antaranya Jakarta, Medan, Tanjung Pinang, Pekanbaru dan Makassar. Adapun negara penerima teratas di kawasan ini adalah Indonesia dengan jumlah 13.653, Thailand 93.000, Malaysia 177.000 dan Bangladash 860.000 pengungsi (UNHCR, 2020).

Regulasi yang diatur pada Peraturan Presiden Republik Indonesia Nomor 125 Tahun 2016 pada Pasal 4 tentang Penanganan Pengungsi dari Luar Negeri telah ditetapkan bahwa seorang pengungsi dari luar negeri tetaplah dianggap sebagai orang asing yang sedang berada di Indonesia dan adanya mereka disebabkan oleh rasa ketakutan karena hal persekusi, yang mana mereka tidak memiliki perlindungan yang memadai dari pemerintah setempat, dan diproses di Indonesia meliputi hasil penemuan, penampungan, pengamanan dan pengawasan (Perpres RI, 2016).

Gambar 1.

Jumlah Pengungsi dan Pencari Suaka di Indonesia Pada Juli 2020

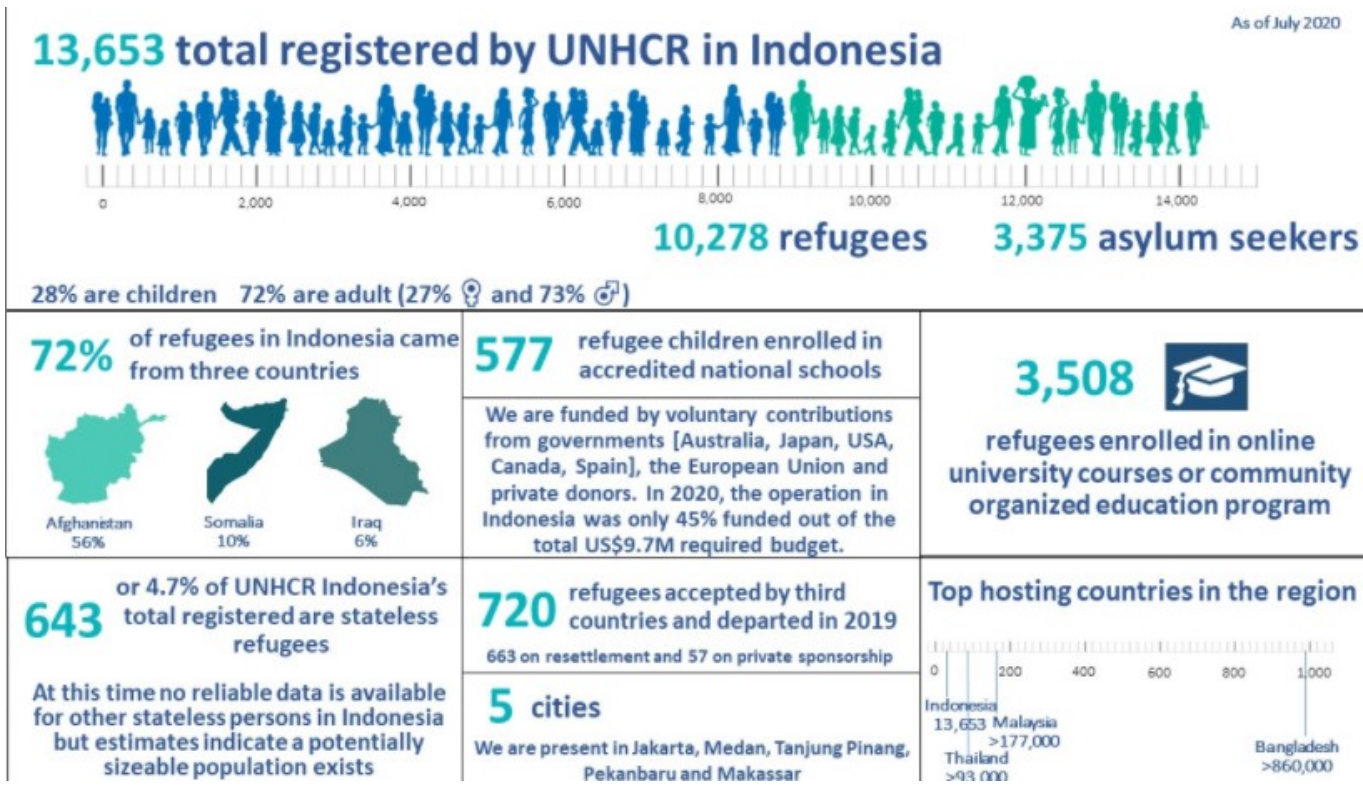

Sumber : (UNHCR, 2020) 
Selain Australia, Malaysia dan Thailand, Indonesia juga sebagai negara penerima pengungsi dan pencari suaka dalam jumlah besar. Pencari suaka yang telah terdaftar dapat melanjutkan proses pengajuan permohonan status pengungsi melalui rangkaian prosedur penilaian yang disebut sebagai Penentuan Status Pengungsi atau Refugee Status Determination (RSD) diberikan kesempatan untuk di-interview oleh petugas yang akan menilai. Kemudian, pencari suaka akan diberikan keputusan dengan pemberian status pengungsi. Jika ditolak, akan ada kesempatan untuk pengajuan banding. Jika lolos mendapatkan status pengungsi, UNHCR akan mencari solusi, terdiri dari penempatan di negara ketiga, pemulangan sukarela apabila konflik sudah berakhir atau integrasi lokal di negara pemberi suaka (UNHCR, 2020).

Pengungsi paling rentan terhadap masalah kesehatan mental (Campbell dkk., 2018). Ada 4 masalah kesehatan mental yang terkait dengan stres pascatrauma yaitu, mengalami kembali dan menghindari kenangan traumatis, reaksi disosiatif, gangguan memori, dan kesulitan dalam mengungkapkan informasi penting tentang pengalaman masa lalu (Tay dkk., 2013). Pengungsi mengalami gangguan psikis dalam proses adaptasi untuk kesehariannya (Leiler dkk., 2019). Terkadang pengungsi juga harus mengalami gangguan lingkungan yang tak biasa dialami dan dipaksa ke dalam budaya baru (Sheikh \& Anderson, 2018). Mayoritas pengungsi dari kalangan anakanak (Hodes \& Vostanis, 2019). Mereka yang berstatus anak-anak harus terpenuhi kebutuhan dasar dan psikologis, serta harus diperhatikan kesehatannya (Cardenas dkk., 2019). Selain itu, anak-anak memiliki hak atas perlindungan dan memperhatikan suara anak-anak pengungsi dengan mempelajari masa lalu dan masa kini mereka, untuk memberi mereka kesempatan mengembangkan potensi tanpa mengabaikan kerentanan mereka (Nho dkk., 2018).

Pengungsi yang terdampar di trotoar jalan kawasan Rumah Sakit Mitra Keluarga
Kalideres, berlindung dengan cara mendirikan tenda seadanya. Motif utama eksistensi mereka sebagai pengungsi yaitu akibat adanya sebuah peperangan. Meskipun mereka sering mendapatkan bantuan dari berbagai pihak, namun, pihak pemerintah harusnya bisa menyelesaikan perkara polemik ini dengan mengambil sikap yang efektif. Pemerintah Indonesia, UNHCR dan para mitra menyadari bahwa banyaknya pengungsi yang rentan dan membutuhkan bantuan, walaupun dengan pendanaan yang terbatas. Pemrosesan solusi seperti penempatan di negara ketiga atau sponsor pribadi, tetap dilakukan menurut prosedur. Sementara ini pengungsi telah dialokasikan di Gedung Pemerintah Daerah yang dekat dengan kawasan pemukiman warga di Kalideres (UNHCR, 2019).

Sebagai tindak lanjut dari (UU No. 39, 1999), dalam menangani persoalan maraknya pergerakan arus pengungsi yang berada di Indonesia, pemerintah pusat bekerjasama dengan Perserikatan BangsaBangsa melalui Komisariat Tinggi Urusan Pengungsi di Indonesia dan atau organisasi internasional mengenai bantuan dan perlindungan yang diberikan untuk pengungsi yang rentan (Sakharina \& kadarudin, 2017). Untuk menuntaskan hal penanganan pemerintah mengenai permasalahan pengungsi yang diakibatkan dari konflik dan membutuhkan perlindungan maka timbul suatu bentuk bantuan dari pemerintah Indonesia berdasarkan prinsip kemanusiaan dan kedaruratan dengan cara memberikan mandatoris melalui Kementerian Luar Negeri dan Kementerian Hukum dan HAM (Rahman \& Bariah, 2013). Dengan demikian permasalahan dalam penelitian ini adalah bagaimanakah bentuk-bentuk bantuan pemerintah dalam penanganan pengungsi di Indonesia? Sementara, tujuan dari penelitian ini adalah untuk mengetahui bentuk bantuan pemerintah dalam penanganan pengungsi di Indonesia. 
Gambar 2.

Penelusuran Literatur

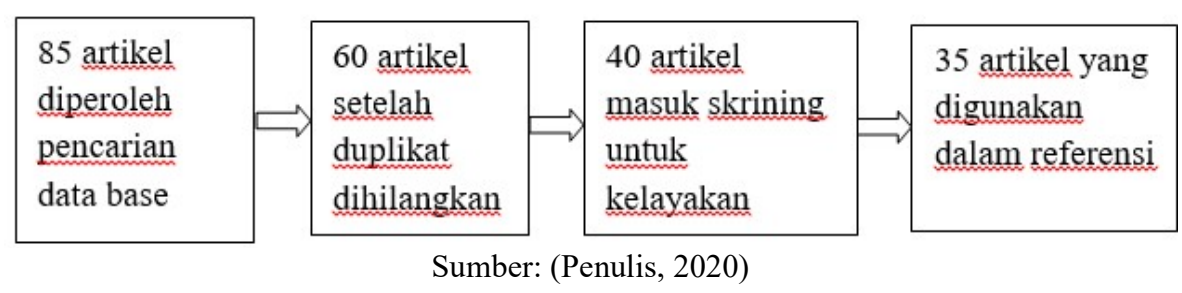

\section{B. Metode Penelitian}

Pada gambar 2 disajikan ilustrasi mengenai metode penelitian yang dilakukan berdasarkan penelusuran literatur.

Penyusunan jurnal menggunakan jenis metode penelitian Sytematic Literature Review (SLR) yang dilakukan dengan cara pendekatan kajian pustaka dari berbagai literatur penelitian yang linear dan terbentuk secara kualitatif deskriptif dengan tinjauan literatur sistematis. Menurut (rawley \& slack, 2004) tinjauan literatur dilakukan untuk memanfaatkan dan mengevaluasi. Penelitian ini bertujuan untuk menganalisis info atau isu terkini dan suatu topik pembahasan yang sebelumnya telah diulas dengan berbagai sumber literatur terdahulu yang sudah disesuaikan dengan perkembangan keilmuan yang relevan.

Artikel diperoleh dari hasil laporan dan berita serta data secara online, yang meliputi, google scholar, science direct, portal garuda, sinta ristekdikti, google cendekia dan garuda ristekdikti. Dengan menggunakan kata kunci human right, refugee, handling, assistance government dan international law. Jenis penelitian ini tidak hanya bermakna membaca literatur saja, namun dominan untuk evaluasi yang mendalam dan kritis tentang penelitian sebelumnya (Kitchenham dkk., 2009).

\section{Hasil dan Pembahasan}

Pengungsi umumnya datang dari negara konflik di Timur Tengah, Asia Tengah dan Selatan, terutama dari Afghanistan, Irak dan Sri Lanka. Sejumlah faktor di antaranya yaitu karena aksesibilitas perlindungan hak asasi manusia dan peluang untuk mencapai wilayah. Selain faktor pendorong ada juga faktor penarik yang berpotensi sebagai negara tujuan akhir, seperti kebijakan imigrasi dan suaka, standar kehidupan yang mempengaruhi pilihan negara transit (Riadussyah, 2016). Pengungsi tidak membayangkan Indonesia sebagai negara tujuan. Namun, Indonesia hanya pos sementara dan batu loncatan menuju Australia, karena telah terbangun reputasi sebagai negara aman dan memberikan perlakuan adil bagi setiap orang serta sebagai negara kaya yang tidak terkena dampak krisis ekonomi global, dengan tingkat pengangguran yang relatif rendah (Riyanto, 2004). Pemerintah Indonesia menempatkan migran transit di rumahrumah detensi imigrasi sebagai sarana perlindungan sementara. Fungsinya untuk memastikan bahwa mereka berada di tempat yang aman dan bisa mendapatkan akses kesehatan dan pendidikan (missbach, 2016).

Dari gambar 3 dinyatakan bahwa jumlah populasi pengungsi di Indonesia dari tahun 2014-2020 mengalami kenaikan yang cukup pesat. Data terakhir yang diperoleh pada bulan Agustus 2020 dengan jumlah pengungsi mencapai 13.680 orang. Juni 1979 UNHCR mendirikan kantor di Jakarta dan menandatangani perjanjian dengan Kementerian Luar Negeri untuk meresmikan hubungan antar keduanya dan memperjelas tanggung jawab antar lembaga. UNHCR Jakarta berkolaborasi erat dengan Kementerian Luar Negeri dan Kementerian Hukum dan HAM agar sama-sama bisa mencari solusi. Namun, tingginya biaya untuk memberlakukan mekanisme pemrosesan pengungsi merupakan hambatan utama. 
Gambar 3. Grafik Populasi Pengungsi

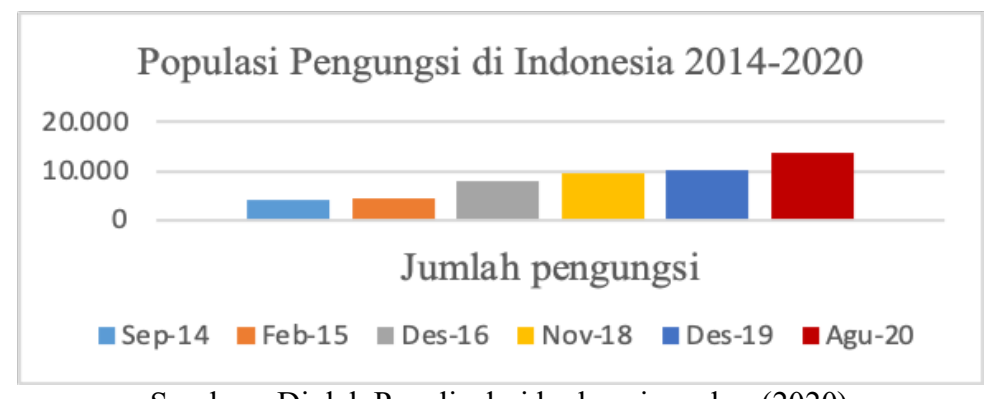

Sumber : Diolah Penulis dari berbagai sumber (2020)

Fakta yang menarik adalah dengan adanya fungsi sistem suaka dalam negeri, Indonesia bersikeras bahwa perlindungan sementara bagi pengungsi sudah cukup. Pemerintah Indonesia sudah bekerjasama dengan UNHCR dan mitra lainnya, khususnya untuk mengembangkan kerangka kerjasama regional. Fungsinya untuk memulangkan orang yang diketahui tidak membutuhkan perlindungan internasional ke negara asal mereka dan lebih mengutamakan perlindungan bagi pencari suaka dan pengungsi yang rentan (UNHCR, 2020).

Pengungsi tidak saja kehilangan rumah, kehilangan kebangsaan dan kehilangan kewarganegaraan melainkan juga kehilangan sandaran hidup termasuk sosial ekonominya (Kofman, 2019). Keputusan untuk pergi mengungsi merupakan sebuah keputusan yang sulit diambil setelah sekian lama berada dalam situasi yang tidak menentu karena segala upaya yang dilakukan tidak berhasil. Pengungsi biasanya tidak dibekali dengan dokumen perjalanan sehingga di antara mereka banyak yang mengalami permasalahan, seperti mereka mengalami perlakuan sewenang-wenang baik di negara asal, negara transit, maupun negara tujuan. Dalam hubungan internasional terdapat nilai yang mengatur sistem pedoman kehidupan global, salah satunya permasalahan pengungsi yang perlu mendapatkan perhatian khusus, maka dari itu terbentuknya hukum pengungsi Internasional yaitu Konvensi 1951 dan Protokol 1967 yang merupakan traktat Universal satu-satunya yang menjabarkan sistem hukum khusus bagi mereka yang membutuhkan perlindungan internasional. Terdapat pula hukum Hak Asasi Manusia Internasional, yaitu hukum yang berlaku bagi setiap orang di dalam negara, baik dia warga negara atau tidak. Hukum internasional tersebut merupakan bagian dari aturan perlindungan terhadap para dimensi penanganan dalam kasus pengungsi internasional (Utami, 2019).

Bagi negara-negara peratifikasi Konvensi, urusan penanganan pengungsi sudah tentu diatur dalam peraturan nasionalnya masing-masing. Namun dalam konteks ini, Indonesia yang bukan sebagai negara peratifikasi, urusan penanganan pengungsi sudah diatur dalam Perpres Nomor 125 Tahun 2016, tidak ditemukan arti sebenarnya dari penanganan pengungsi, namun diatur mengenai pihak-pihak terkait dalam menangani pengungsi luar negeri (Pasal 7) mengenai proses operasi pencarian dan pertolongan. Selain itu, diatur juga mengenai perumusan kebijakan penanganan oleh menteri terkait menyangkut penemuan, penampungan, pengamanan dan pengawasan keimigrasian (Pasal 4). Kerjasama penanganan pengungsi secara jelas tercantum dalam (Pasal 2), yaitu antara pemerintah Indonesia dengan UNHCR. Dengan demikian penanganan pengungsi sesungguhnya telah diakui oleh pemerintah Indonesia. Menurut Perpres ini, penanganan pengungsi dilakukan berdasarkan kerja sama antara pemerintah pusat dengan Perserikatan Bangsa-Bangsa (PBB) melalui Komisariat Tinggi Urusan Pengungsi di Indonesia dan 
atau organisasi internasional, yang merupakan organisasi internasional di bidang urusan migrasi atau di bidang kemanusiaan yang memiliki perjanjian dengan pemerintah pusat (Rachman, 2018).

Selama ini pola penanganan pengungsi internasional adalah dengan cara penempatan di negara lain (resettlement), integrasi dengan negara ketiga atau menjadi warga negara resmi di negara ketiga (integrasi) dan pengembalian ke negara asal pengungsi (repatriasi). Solusi seperti ini tentulah bukan tanpa hambatan. Terdapat banyak kendala bila memilih jalan keluar seperti ini. Apalagi dikaitkan dengan status sebagai negara transit dan pilihan tersebut adalah solusi jangka panjang (Yuningsih, 2013). Contohnya seperti Indonesia yang bukan termasuk negara peratifikasi, jadi tidak bisa bertanggung jawab secara langsung terhadap pengungsi. Namun, Indonesia sebagai anggota PBB hanya bisa memberikan tanggung jawab moril berupa bantuan kemanusiaan. Menindaklanjuti dalam bentuk penanganan yaitu, melakukan peran aktif dalam monitoring dan mengevaluasi penanganan isu kemanusiaan dalam kerangka PBB dan juga secara konsisten menyampaikan kontribusi sukarela tahunan yang berjumlah USD $\$ 220.000$ mulai tahun 2017 (Kementerian Luar Negeri, 2019), serta tetap memperjuangkan hak asasi manusia terhadap pengungsi, karena bagaimanapun semua manusia tidak ada yang bisa disebut ilegal, melainkan hanya faktor keterbatasan administrasi (Pavlich, 1996).

Berdasarkan wawancara dengan Axelsyah Reza dari Kementerian Luar Negeri Indonesia bagian Direktorat Jendral HAM dan Kemanusiaan mengatakan bahwa, data pengungsi di Indonesia per Agustus 2020 ini sudah mencapai 13.680. Alasan memilih ke Indonesia bukan karena kondisi politik dan ekonomi yang buruk di kampung halaman mereka, tapi karena diskriminasi terhadap kelompok agama dan etnis minoritas. Tidak dibenarkan apabila permasalahan dalam bentuk ekonomi, karena mereka harus memiliki biaya besar untuk menuju dan bertahan hidup di negara transit. Indonesia bukan merupakan negara penandatangan konvensi pengungsi dan protokolnya, sehingga Indonesia tidak bisa menawarkan hak-hak resmi pada pencari suaka dan pengungsi di wilayahnya, namun mentolelir keadaan mereka selama menjalankan penentuan status pengungsi di bawah UNHCR atau telah mendapatkan pelayanan ke IOM (International Organization for Migration). Saat ini pemerintah Indonesia hanya bisa melakukan berdasarkan prinsip kemanusiaan dan kedaruratan dengan cara mendata pengungsi yang datang dan menempatkan mereka sementara ke lokasi yang aman; memberikan fasilitas sesuai kebutuhan pengungsi, seperti tempat bermain dan belajar anak-anak, wadah untuk berolahraga, juga fasilitas kesehatan yang mumpuni. Dengan adanya UNHCR di Indonesia, dimiliki dana tahunan sebesar USD \$1.706.832.053 untuk pengungsi dan donor terbesarnya adalah Amerika Serikat. Sejak tahun 2012 pemerintah Indonesia ikut berkontribusi dana sebesar USD $\$ 50.000$ kepada UNHCR. Mengingat terbatasnya dana menjadikan proses pengajuan dan penentuan status pengungsi membutuhkan waktu bertahun-tahun (Reza, 2020).

Dari hasil wawancara oleh salah satu pengungsi yang berasal dari Afghanistan, Jason Arr Mahran mengatakan bahwa, kepergian dari negara asal karena adanya konflik yang terjadi sejak tahun 2001 tujuannya untuk mencari perlindungan dan terpisah dengan beberapa anggota keluarga yang tersebar di India dan Arab. Ia datang ke Indonesia menggunakan uang pribadi dengan cara menjual barang berharga dan datang tanpa dokumen yang lengkap. Di Indonesia pernah mengungsi di Kepulauan Riau, Cianjur dan terakhir di Jakarta, kemudian bertahan hidup sebisa mungkin dengan keterbatasan, yang terpenting terbebas dari konflik. Pengungsi merasakan pemerintah Indonesia sudah cukup membantu, bahkan ada pula bantuan berasal dari warga sekitar, setidaknya tempat sementara untuk berlindung. Namun, ada 
beberapa hal yang diharapkan untuk pemerintah Indonesia, yaitu proses yang lebih cepat dan efektif, terkhusus untuk pengungsi yang rentan, seperti anak-anak dan perempuan (Mahran, 2020).

Untuk memastikan bahwa perlindungan dilaksanakan secara sistematis, pemerintah Indonesia telah melakukan berbagai tindakan dalam hal penanganan pengungsi, dengan cara repatriasi sukarela, integrasi lokal dan perpindahan ke negara ketiga. Namun, repatriasi sukarela tetap merupakan pilihan solusi yang paling dicari oleh pengungsi, tetapi tidak selalu mudah untuk dicapai jika persyaratan yang diperlukan untuk keperluan tidak memadai. Agar berhasilnya repatriasi sukarela, harus mendapatkan dukungan penuh dan komitmen dari negara tempat pengungsi. Hal ini dikarenakan, bagaimanapun bagi pemerintah Indonesia repatriasi sukarela adalah solusi yang efektif, sebab biayanya lebih murah dari pada proses deportasi (Lenette dkk., 2019). Melakukan repatriasi sukarela yang mencakup unsur penting seperti, hak seseorang pulang ke negaranya sesuai dengan hukum hak asasi internasional, kecuali jika dibatasi oleh hukum tertentu dan telah pulih konflik di negara asalnya. Oleh karena itu, unsur pokok dari repatriasi sukarela adalah kembali ke suasana aman dengan bermartabat (Sakharina \& kadarudin, 2017). Data per Agustus 2020 dari total pengungsi sudah diterima oleh negara ketiga 222 pengungsi, sedangkan 71 pengungsi telah diproses untuk repatriasi (UNHCR, 2020).

Faktanya kondisi pengungsi berada dalam keadaan hidup yang memprihatinkan serta penuh dengan ketidakpastian. Pesatnya pertumbuhan jumlah pengungsi internasional sangat mengkhawatirkan. Mereka lari dari negara asalnya demi untuk menyelamatkan dari hinaan pihak yang sudah melanggar nilai-nilai kemanusiaan (Mayblin \& James, 2019). Pengungsi tidak mendapat perlindungan dari negaranya sendiri, bahkan seringkali pemerintahnya sendiri yang menganiaya mereka, sehingga melarikan diri adalah pilihan terbaik (Alam dkk., 2020). Selanjutnya, mereka kembali menghadapi masalah di negara transit bahkan di negara ketiga. Perpindahan ini malah menimbulkan masalah baru, menjadi sangat rentan terhadap pemenjaraan, pendeportasian, pemanfaatan dan berbagai perlakuan buruk lainnya (Yani \& Zulkarnain,2019).

Bantuan pemerintah Indonesia terhadap pengungsi internasional, mengacu pada pemenuhan pemberian hak asasi manusia terhadap pengungsi, yang mana Desire Frans mengatakan bahwa, HAM merupakan hak yang diperoleh seseorang karena dia manusia dan bersifat universal. Untuk pemenuhan HAM terhadap pengungsi, pemerintah memprioritaskan hak dasar pengungsi yang mutlak dalam masyarakat nasional maupun internasional yang meliputi semua hak yang diperlukan untuk memenuhi kebutuhan manusia baik dalam hal material maupun non-material, di antaranya hak hidup, hak atas keamanan, hak mendapatkan fasilitas kesehatan, hak kebutuhan tempat tinggal, hak untuk tidak diganggu dan bebas dari penyiksaan, diskriminasi dan tindakan lain yang bisa mengurangi martabat manusia (Ashri, 2018). Untuk menjamin hak dasar pengungsi, pemerintah Indonesia memberikan bantuan dalam bentuk penemuan, penampungan, pengamanan dan pengawasan keimigrasian, yang diwujudkan dengan cara pendataan, memberikan fasilitas tempat tinggal sementara, memberikan fasilitas kesehatan fisik dan mental untuk pengungsi, agar bisa meminimalisir rasa trauma pengungsi (Krustiyati, 2010).

Dalam hal ini pemerintah Indonesia memberikan solusi jangka pendek berupa fasilitas sementara dengan cara mengalokasikan pengungsi ke gedung Pemerintah Daerah DKI Jakarta dan tetap mengupayakan proses jangka panjang berupa dukungan moril untuk pengungsi dengan cara melakukan diplomasi kemanusiaan. Tujuannya untuk meredakan konflik dan mencapai penyelesaian yang permanen (Tyler, 2013). Dari hasil pembahasan ini menunjukan bahwa pemerintah Indonesia hanya bisa melakukan 
peran dan tanggung jawabnya yang terbatas, berupa bantuan kemanusiaan dan prinsip kedaruratan.

\section{Simpulan}

Indonesia sudah dianggap menjadi negara transit yang paling populer oleh pengungsi, dengan alasan lokasinya yang strategis. Walaupun Indonesia bukan menjadi negara penandatangan konvensi internasional, namun Indonesia telah menjalankan toleransi secara efektif. Indonesia sangat selektif dalam penentuan status pengungsi, agar tepat sasaran dalam perbantuan. Sebagaimana yang telah di tetapkan, Indonesia tidak bisa menawarkan hak-hak yang pengungsi harapkan, melainkan harus sesuai protokol. Menangani pengungsi internasional merupakan sebuah tanggung jawab negara dan komunitas sosial global, tidak hanya negara yang bersangkutan ikut meratifikasi pengungsi 1951 atau tidak. Hal ini dikarenakan, persoalan pengungsi internasional adalah persoalan universalisme kemanusiaan, termasuk di dalamnya hak asasi manusia, jadi tidak ada alasan untuk mengabaikan. Maka dari itu, pemerintah Indonesia hanya bisa memberikan solusi berupa bantuan dengan aspek kemanusiaan dan kedaruratan.

Bentuk bantuan pemerintah dalam penanganan pengungsi di Indonesia berupa tempat penampungan sementara, memberikan fasilitas kesehatan dan pendidikan untuk pengungsi, khususnya pada pengungsi yang rentan seperti anakanak dan perempuan. Nilai kemanusiaan tidak dapat dipisahkan dari dimensi pengelolaan negara, karena manusia pada hakikatnya mempunyai perilaku yang saling menghargai sesama. Untuk itu tindakan penanganan pengungsi adalah aksi yang berlandaskan akal sehat. Penanganan juga bisa dipilih berdasarkan aturan yang sesuai dengan hukum pengungsi internasional, namun demikian tidak terbatas sifatnya, melainkan tidak bertentangan dengan sudut pandang kemanusiaan.

\section{DAFTAR PUSTAKA}

Alam, A., Sammonds, P., \& Ahmed, B. (2020). Cyclone risk assessment of the Cox's Bazar district and Rohingya refugee camps in southeast Bangladesh. Science of The Total Environment, 704, 135360.

https://doi.org/10.1016/j.scitotenv.2019. 135360

Anggrainy, V. S. (2014). Perlindungan Pengungsi Lintas Batas Negara Di Indonesia Menurut Hukum Internasional. 1, 10.

Ashri, M. (2018). Hak Asasi Manusia: Filosofi, Teori \& Instrumen Dasar. CV. Social Politic Genius (SIGn).

Barber, B. K., Spellings, C., McNeely, C., Page, P. D., Giacaman, R., Arafat, C., Daher, M., El Sarraj, E., \& Mallouh, M. A. (2014). Politics drives human functioning, dignity, and quality of life. Social Science \& Medicine, 122, 90102. https://doi.org/mamung

Campbell, M. R., Mann, K. D., Moffatt, S., Dave, M., \& Pearce, M. S. (2018). Social determinants of emotional wellbeing in new refugees in the UK. Public Health, 164, 72-81. https://doi.org/10.1016/j.puhe.2018.07.0 22

Cardenas, D., Bermudez, C., \& Echeverri, S. (2019). Is nutritional care a human right? Clinical Nutrition Experimental, 26, $1-7$. https://doi.org/10.1016/j.yclnex.2019.05 .002

Dreher, A., Fuchs, A., \& Langlotz, S. (2019). The effects of foreign aid on refugee flows. European Economic Review, 112, 127-147. https://doi.org/10.1016/j.euroecorev.201 8.12 .001

Hardjaloka, L. (2015). Studi perbandingan ketentuan perlindungan pencari suaka dan pengungsi di indonesia dan negara 
lainnya.

http://garuda.ristekbrin.go.id/documents /detail/266061

Hodes, M., \& Vostanis, P. (2019). Practitioner Review: Mental health problems of refugee children and adolescents and their management. Journal of Child Psychology and Psychiatry, 60(7), 716-731. https://doi.org/10.1111/jcpp.13002

Hvass, A. M. F., Norredam, M., Sodemann, M., Thomsen, M. K., \& Christian, W. (2020). Are refugees arriving in Denmark an under-immunised group for measles? A cross-sectional serology study. Vaccine, 38(13), 2788-2794. https://doi.org/10.1016/j.vaccine.2020.0 2.025

Kementerian Luar Negeri, kementerian. (2019). Isu Isu Kemanusiaan | Portal Kementerian Luar Negeri Republik Indonesia.

https://kemlu.go.id/portal/id/read/88/hal aman_list_lainnya/isu-isu-kemanusiaan

Kitchenham, B., Pearl Brereton, O., Budgen, D., Turner, M., Bailey, J., \& Linkman, S. (2009). Systematic literature reviews in software engineering - A systematic literature review. Information and Software Technology, 51(1), 7-15. https://doi.org/10.1016/j.infsof.2008.09. 009

Kofman, E. (2019). Gendered mobilities and vulnerabilities: Refugee journeys to and in Europe. Journal of Ethnic and Migration Studies, 45(12), 2185-2199. https://doi.org/10.1080/1369183X.2018. 1468330

Krustiyati, A. (2010). Penanganan Pengungsi di Indonesia: Tinjauan Aspek Hukum Internasional dan Nasional. Briliant Internasional.

Leiler, A., Bjärtå, A., Ekdahl, J., \& Wasteson, E. (2019). Mental health and quality of life among asylum seekers and refugees living in refugee housing facilities in Sweden. Social Psychiatry and Psychiatric Epidemiology, 54(5), 543-551.

https://doi.org/10.1007/s00127-018-

1651-6

Lenette, C., Brough, M., Schweitzer, R. D., Correa-Velez, I., Murray, K., \& Vromans, L. (2019). 'Better than a pill': Digital storytelling as a narrative process for refugee women. Media Practice and Education, 20(1), 67-86. https://doi.org/10.1080/25741136.2018. 1464740

Mahran, J. A. (2020). Hasil Wawancara Pengungsi.

Mayblin, L., \& James, P. (2019). Asylum and refugee support in the UK: Civil society filling the gaps? Journal of Ethnic and Migration Studies, 45(3), 375-394.

https://doi.org/10.1080/1369183X.2018. 1466695

missbach, antje. (2016). Trobled Transit (politik indonesia bagi para pencari suaka). yayasan pustaka obor indonesia.

Moorthy, S., \& Brathwaite, R. (2019). Refugees and rivals: The international dynamics of refugee flows. Conflict Management and Peace Science, 36(2), 131-148. https://doi.org/10.1177/0738894216657 047

Nagel, C., \& Boyle, P. (2020). Migration. Dalam International Encyclopedia of Human Geography (hlm. 81-88). Elsevier. https://doi.org/10.1016/B9780-08-102295-5.10287-2

Nho, C. R., Yoon, S., \& Ko, J. (2018). Voices of refugee children in Korea. Children and Youth Services Review, 94, 606-616. https://doi.org/10.1016/j.childyouth.201 8.09.001

Pavlich, G. (1996). The Power of Community Mediation: Government and Formation of Self-Identity. Law \& 
Society Review, 30(4), 707. https://doi.org/10.2307/3054115

PerPres RI. (2016). PerPres RI No. 125 BAB 1 Ayat 1 tentang penanganan pungungsi dari luar negeri.

Prastya, A. B., \& Yuniati, S. (2015). FaktorFaktor yang Mempengaruhi Kebijakan Australia terhadap Imigran Gelap pada Masa Pemerintahan Partai Buruh Australia. Jurnal Ilmu.

Rachman, M. I. J. (2018). Kerjasama Indonesia Dengan Lembaga-Lembaga Terkait Dalam Penanganan Pengungsi. Jurist-Diction, 1(1), 262-285. https://doi.org/10.20473/jd.v1i1.9745

Rahman, A., \& Bariah, C. (2013). Abstrak Perlindungan Dan Penegakan Ham Di Asean Terhadap Manusia Perahu Rohingya Dalam Status Sebagai Pengungsi Menurut Hukum Internasional 080200082. 21.

rawley, jennifer, \& slack, frances. (2004). Conducting a Literature Review.

Reza, A. (2020). Hasil wawancara Kementerian Luar Negeri bagian Direktorat Jendral HAM dan Kemanusiaan.

Riadussyah, M. (2016). Tanggung Jawab Indonesia sebagai Negara Transit bagi Pengungsi Anak Berdasarkan Hukum Internasional. Jurnal Hukum IUS QUIA IUSTUM, 23(2), 330-250. https://doi.org/10.20885/iustum.vol23.is s2.art4

Riyanto, S. (2004). Urgensi Legislasi Hukum Pengungsi dan Kendalanya di Indonesia. Indonesian J. Int'l L., 2, 67.

Sakharina, I. K., \& kadarudin. (2017). Pengantar Hukum Pengungsi Internasional (Perbedaan pencari suaka, pengungsi internasional, dan pengungsi dalam negeri). Deepublisher.

Sheikh, M., \& Anderson, J. R. (2018). Acculturation patterns and education of refugees and asylum seekers: A systematic literature review. Learning and Individual Differences, 67, 22-32. https://doi.org/10.1016/j.lindif.2018.07. 003

Suwardi, S. S. (2004). Aspek Hukum Masalah Pengungsi Internasional. Indonesian J. Int'l L., 2, 23.

Tay, K., Frommer, N., Hunter, J., Silove, D., Pearson, L., San Roque, M., Redman, R., Bryant, R. A., Manicavasagar, V., \& Steel, Z. (2013). A mixed-method study of expert psychological evidence submitted for a cohort of asylum seekers undergoing refugee status determination in Australia. Social Science \& Medicine, 98, 106-115. https://doi.org/10.1016/j.socscimed.201 3.08 .029

Thompson, D. K. (2020). Refugees and Asylum Seekers. Dalam International Encyclopedia of Human Geography (hlm. 221-228). Elsevier. https://doi.org/10.1016/B978-0-08102295-5.10340-3

Tyler, I. (2013). The Riots of the Underclass?: Stigmatisation, Mediation and the Government of Poverty and Disadvantage in Neoliberal Britain. Sociological Research Online, 18(4), 25-35. https://doi.org/10.5153/sro.3157

UNHCR. (2019). Information-on-GedungPemda-Kalideres-Bahasa-

Indonesia.png $(925 \times 822)$ https://www.unhcr.org/id/wpcontent/uploads/sites/42/2019/07/Infor mation-on-Gedung-Pemda-KalideresBahasa-Indonesia.png

UNHCR. (2020). Sekilas Data-UNHCR Indonesia. UNHCR https://www.unhcr.org/id/figures-at-aglance

Utami, P. N. (2019). Implementasi Peraturan Presiden Nomor 125 Tahun 2016 Tentang Penanganan Pengungsi Dari Luar Negeri Di Provinsi Kepulauan 
Riau. Jurnal Legislasi Indonesia, 16(3), 299-312.

UU No 39. (1999). UU No 39 Tahun 1999.

Yani, Y. M., \& Zulkarnain, Z. (2019). Dimensi Penanganan dalam Kasus Pengungsi Internasional; Teori dan Praktik. Jurnal Sosial dan Humaniora, 4(7), Article 7. https://doi.org/10.47313/ppl.v4i7.592

Yuningsih, A.-. (2013). Implementasi Perlindungan Hukum Bagi Pengungsi
Asal Afghanistan Di Wilayah Indonesia Di Tinjau Dari Perspektif Konvensi 1951 Dan Protokol 1967 Mengenai Status Pengungsi Studi Kasus Di Pontianak Kalimantan Barat. Jurnal Hukum Prodi Ilmu Hukum Fakultas Hukum Untan (Jurnal Mahasiswa S1 Fakultas Hukum) Universitas Tanjungpura, 1(3). http://jurnal.untan.ac.id/index.php/jmfh/ article/view/3134 